\title{
Managing Communication Challenges in Multicultural Organizations
}

\author{
Shafaat Hussain* \\ Assistant Professor of Journalism and Communication, MaddaWalabu University, Bale-Robe, Oromiya Region, \\ Ethiopia
}

*Corresponding Author: Shafaat Hussain, Assistant Professor of Journalism and Communication, MaddaWalabu University, Bale-Robe, Oromiya Region, Ethiopia

\begin{abstract}
Multicultural organizations are the hubs of various cultures hailing from across the world. Managing communication challenges in culturally diverse global teams is indeed a herculean task. Effective communication in multicultural organizations is similar to a human neural network; and once it fails the entire system gets dysfunctional. In a multicultural organization, communication is a powerful tool through which information is exchanged; trust is built; and constructive relationship is maintained. This paper primarily reviews the literatures on the concept of multicultural organizations. The second section deals with the available opportunities for communication in a multicultural set-up. The third part discusses the various dimensions of communication in a multicultural organization. The fourth section argues the possible challenges of communication in a multicultural organization. And, the final section proposes the ways, how multicultural organizations manage their communication challenges.
\end{abstract}

Keywords: Communication, Multicultural Organization, Cross-Cultural, Stereotyping, Ethnocentrism.

\section{INTRODUCTION}

Multiculturalism is a reality the way world is globalized in the social sphere, political system, economic landscape, geographical areas, and international relations. Multicultural organizations (MCOs hereafter)are omnipresent in the current economic system; and we are persistently surrounded by diverse cultures; therefore, workforce diversity is becoming the common feature of the MCOs. The size and number of the organizations operating across the globe is also growing very fast. Consequently, the diversity is more in the consumer base, client groups, and partners (Sudhiir and Sudhiir, 2016:95). An organization wherein the people of diverse culture work together in order to achieve certain common goals is known as a "multicultural organization." MCOs are the hubs of various cultures hailing from across the world. At the present time, these MCOs possess a larger proportion of organizational workforce throughout the world's economy. Since this workforce has huge potential to organizations improving their effectiveness in the global business environment, they require deep understanding of mixed skills of employees from different nations. (Cox, 1993; Galbraith, 2000; Kirchmeyer and McLellan, 1991; Kirkman and Shapiro, 2001; Tung,1993).

There are many instances of cultural variants in the different parts of the world. Knowing these differences can simplify the functions of both multinational employers and employees. Knowing the cultural diversity helps in team building, trust formation, conflict resolution, effective collaboration, and more importantly assess the performance of the team members (Binder, 2007; McDonough, 2001:111).For example, East Asians presume that the people from Western countries treat strangers like friends; and friends like strangers. Communication in Western cultures is generally direct and explicit. The meaning of the message is very clear. But, this isn't the case in other countries, like Japan, where formality and etiquettes play a major role in their communication. For some cultures, eye contact is considered as discourteous while for others refraining from the same is considered as disrespectful. Further, in Western cultures, and in Africa, giving a hug is considered very informal and fine but it may not be so in Asian countries. Furthermore, some cultures treat women as subordinate and for men belonging to such cultures it becomes near impossible to working shoulder to shoulder or having women as their superiors. Additionally, in some cultures the appropriate greeting is a handshake, in others a bow, in others an embrace. It is cited in a study that Arabs, Latin Americans 
and Southern Europeans look into the eyes of conversational partners whereas Asians and North Europeans only use a peripheral gaze or no gaze at all during interactions. 'Silence' is indicated as respect among Chinese people while it is interpreted as shyness or lack of interest among Australians. Similarly, 'touch' has different meanings in different cultures. In Thailand it is considered rude to touch to strangers; whereas in Ethiopia, walking hand in hand with friends and opposite sex indicates a romantic relationship (Sudhiir and Sudhiir, 2016:97). Thus, difference in communication approaches, understandings, attitudes, and styles, is inevitable phenomenon among the diverse workforce of MCOs.

\section{FEATURES OF MCOS}

The literature is both consistent and clear in demonstrating the power and potential of the MCOs. The prominent features of MCOs are that they hire the best available human talent; possess high morale, and collective positivity among workers; have broader perspectives and deeper ideas; and hold openmindedness and tolerance. Moreover, MCOs are more efficient and productive; technologically more sound; more competitive; and higher in creativity and innovation due to their diverse background. In addition to it, they have sound relationships with key partners in foreign markets; and encompass greater problem solving ability. Equipped with the better decision making abilities, MCOs exhibit change and flexibility, and they have large virtual network (Kiss, 2005:220; Singh, 2014:46; Vashishtha \& Garg, 2014:3-4; Heyman 2017:21).

\section{CONCEPTUALIZING COMMUNiCATION In MCOS}

Organizational communication is the study of communication within organizations. The flow of communication within an organization is multifaceted: formal and informal, vertical and horizontal, verbal and non-verbal, and written and oral. Managing communication in a MCO is indeed a herculean task. Communication in multicultural organizations is like a neural network in the human body; and if there is a fall through, the organism becomes inefficient or even dysfunctional. Similarly, in a multicultural organization, it is only through the effective communication that the information is shared, trust is built, and constructive relation is developed and maintained. Organizational communication is as broad in its domain as the field of communication itself. Indeed, Iedema and Wodak (1999:7) stated that organizations do not exist self-reliantly of their members, but are "created and recreated in the acts of communication between members." Communication in organization is "the central means by which individual activity is coordinated to devise, disseminate, and pursue organizational goals" (Gardner, Paulsen, Gallois, Callan, \& Monaghan, 2001:561). Organizations typically involve highly differentiated social systems (Scott, 1997; Trice \& Beyer, 1993), with formal and informal frontiers and negotiated distinctiveness. Because MCOs are at the state of continual change, communication processes are also changing both to create and to reflect the new structures, processes, and relationships. MCOs which fail to apprehend the cross cultural communication barriers face several problems in many aspects of international business communication as it encompasses free trade policies, localization and standardization strategy decisions, advertising, brand effectiveness, business relationships, international business management, international marketing, international negotiation, and consumer behavior, staffing, industrial relations, interpersonal relationships, negotiation, and teambuilding (Jenifer and Raman 2015:332).

\section{Communication Challenges in MCOS}

Communication challenges are bound to come in the MCOs. The significant communication challenges in MCOs are: language barrier, stereotyping, ethnocentrism, cultural relativism, cultural shock, attitude toward conflict resolution, task completion, decision making, privacy, trust building, and non-verbal language.

\subsection{Language Barrier}

Language barrier is the most common problem found in MCOs as staffs have more chances of meeting and dealing with the speakers of other languages (Jenifer and Raman 2015:334). There is no denying the fact that English is the lingua franca of the modern economic world; and it has become the official standard language for business throughout the globe; however, because of this many nonEnglish speakers can be overlooked and unrewarding because of their incompetence to communicate and comprehend English, and thus convey what they want to say. Even sometimes, there are chances the managers take a backseat as they are unable to convey their message crossways. This leads to 
thwarting and constant worry over a passage of time, and certainly it affects the productivity of the organization (Sudhiir\&Sudhiir, 2016:97).

\subsection{Stereotyping}

Stereotyping is the notion that we carry about a certain set of people and their culture, value judgments, overestimation or over-exaggerations. These stereotypes are the main reasons for difference of opinions about the conflicting culture and leads to miscommunication (Jenifer \& Raman 2015:332; Sudhiir\&Sudhiir, 2016::96). The popular examples of stereotypes are: Spanish people are bad-tempered and racist; the English are business men; Chinese people make work their religion, Swiss people like exactness, Brazilians are always late, and Japanese are forward-looking. All these ideas are stereotypes against a country and its people, which can negatively affect the working employees or future employees. Because of already-made suppositions, an employer can demonstrate bias and make a mistake in hiring, operation, and firing (Heyman 2017:19).

\subsection{Ethnocentrism / Cultural Relativism}

Ethnocentrism is defined as a cultural superiority complex: rationalizing that one's own culture or group behavior is advanced against all the other groups. It is an attitude wherein one's own cultural experience unintentionally makes us to feel that our culture is distinctive. This feeling further increases the level of the anxiety, which in turn affects the productivity of the working culture (Jenifer \& Raman 2015:332; Sudhiir\&Sudhiir, 2016:96). The workforce of MCO faces a lot of issues due to ethnocentrism. Ethnocentrism interferes with interaction to other cultures and proves a barrier of communication. International workforces need cultural understanding of local conditions to multiply competence and productivity (Singh, 2018:48).

Cultural relativism is the belief where in one compares the standards and conducts of target cultures and gauges them against the norms of what's incorrect and what's correct. This becomes a hurdle when one presumes that cultural norms, customs and traditions are not right if they vary from those of the other culture (Sudhiir\&Sudhiir, 2016:97).

\subsection{Cultural Shock}

Cultural shock is the accidental encounter of an employee with some unknown and unexpected cultural practice. When employees enter another nation or territory, they tend to undergo cultural shock, which is the diffidence and bewilderment caused by encountering a different culture. They may not be acquainted with how to act, may fear losing face and self-confidence, or may become emotionally disappointed. Some individuals segregate themselves, while a few even decide to come back home from the next flight. Cultural shock is virtually universal, which happens even on a migration from one advance nation to another (Singh, 2014:47-48).

\subsection{Attitude toward Conflict Resolution}

Attitude toward conflict play a vital role for the working place, especially in the team work. The different cultures of the world resolve clashes in the different ways. For example, the people of United States take conflicts positively, and like to solve it directly, and face-to-face; whereas, for Easterners conflict is a negative undertone and they like to resolve the conflicts quietly or silently(Kiss, 2005:216).

\subsection{Approaches to Tasks' Completion}

Westerners accomplish one task at a time, and they are individualistic; whereas, the Asians and African accomplish many tasks at a time, and they are collectivistic in modes operandi. Individualistic cultures like United States and France are more self-centered and emphasize mostly on their individual goals. People from individualistic cultures tend to think only of themselves. They emphasize their achievements in job or private wealth and aiming up to reach more and/or a better job position. Especially, in the USA the fight about jobs and trying to climb up in the hierarchy ladder is something very common. It just counts to get there, less caring of who will be left behind. In contrast, collectivistic cultures have a great emphasis on groups and think more in terms of "we" rather than "I". For collectivists, harmony and loyalty is very important and is always maintained and confrontation is avoided. In China, it is out of the question to disagree with someone's opinion in public. One has to do that in a more private and personal atmosphere to protect a person from the 
"loss of face." In collectivistic cultures, a direct confrontation is always avoided. Expressions or phrases are used which describe a disagreement or negative statement instead of saying "no" clearly. Saying "no" would mean to disrupt the synchronization in the group. The relationship between employer and employee or business partners is based on trust, harmony, and a deep understanding of ethical values (Kiss, 2005:216).

\subsection{Different Decision-Making Styles}

Decision making abilities are found higher and deeper with MCO managers. The reason behind this is the diverse natures of decision they take day to day meetings. A successful workforce is well aware with the styles of different cultures in taking decision. The roles individuals play in decision-making vary widely from culture to culture. For example, when decisions are made in group, the "rule of majority" is a common approach among the US people whereas in Japan "consensus" is preferred mode in decision making style (Kiss, 2005:216).

\subsection{Different Attitudes toward Privacy}

Privacy is the important element of a culture. It is a mindset, which is related to the efficiency and productivity. If managers of MCOs will properly know about the attitudes toward privacy of the employee, he/she can accrue better competence among them. Different cultures in the world have different orientation towards privacy. It is interesting to know that for instance, Americans have a low degree of privacy, and most of the time they prefer to be in public. That means, they expose and show-up more in public, friends, and staff members. On the contrary, the people of Germany, France, China etc. are enclosed people. They have high degree of privacy, and they share just a low percentage with public (Shanthi, 2014:50).

\subsection{Different Ways of Building Trust and Relationship}

There is a strong association between the trust and productivity. Cultural differences play a vital role in the creation of trust and relationship. For instance, in the United States, trust is demonstrated performance over time. Here one can gain the trust of his/her colleagues by "coming through" and delivering on time on his/her commitments. In many other parts of the globe, including many Asian and Latin American nations, building relationships is a prerequisite for professional interactions. Building trust in these countries often involves lengthy discussions on non-professional topics and shared meals in the restaurants. Work- related discussion starts only once his/her counterpart has become comfortable with him/her as a person. Cultural difference in multicultural teams can create misunderstanding between team members before they have had a chance to establish any credibility with each other. Thus, building trust is a critical step in creation and development of MCO teams (Shanthi, 2014:50).

\subsection{Non-Verbal Communication}

Many communications are done through physical gestures, tone, touch, expressions without using words. Folded arms, crossed legs are defensive whereas music, dance, painting, sculpturing are creative and aesthetic non-verbal communication. The examples of non-verbal communication are: facial expression, body movement, posture and gestures, personal appearance, dressings, touch, colors, silence, proxemics (science of reflecting relationship that refers to space between two people when they communicate), paralanguage (the vocal characteristics and sounds that adds flavor to words), pitch (raising or lowering of our voice), tempo (variation in speaking too fast or slow), resonance (the variation of volume from a thin voice to loud), and quality of voice, add a lot of flesh and blood to the words. Non-verbal communication plays an important role in any communication situation. It often plays a supplementary role to the verbal content delivered orally. People with different cultures have different styles of non-verbal communication. Knowledge of different nonverbal communications is essentially very important so as to avoid the misunderstanding and other barriers of communication. They differ in the rules for turn-taking, the use of silence, the posture, the eye contact, the proximity, the touch, the tone of voice, the node, the facial expression, the gesture, and so on (Sudhiir and Sudhiir, 2016:96).

\section{OVERCOMing COMMUNiCATION ChaLlenges in MCOS}

The key to effective cross cultural communication and thereby overcoming the pitfalls is knowledge. Therefore, it is essential that people understand the potential communication problems of MCOs, and 
make a conscious effort to overcome these problems. There are a number of steps that a MCO can take to overcome the communication challenges, and they are careful hiring, language training, cross cultural knowledge training, sustainable communication platform, and assignments as per experience and interest (Singh, 2014:48-49; Shanthi, 2014:52; Vashishtha\&Garg, 2014:4).Firstly, hiring staffs in MCOs should be carefully evaluated on the entry point either in oral fashion or in written. While hiring employees, there should be a mechanism to check the degree of ethnocentrism through oral or written way. Those candidates can be selected who are low in the score of ethnocentrism and other possibly troublesome characteristics. The desire to experience other culture and live in another nation may also be an important prerequisite attitude worth assessing. Learning the attitude of employees' spouse toward the assignment also can be important to ensure that there is strong support for serving in foreign country. Secondly, once appointed language training support is the second requisition of the employee of a MCO. Many organizations try to hasten adjustment to a host nation by encouraging employees to learn local language, or lingua franca. They offer training prior to assignments. It often includes orientation to the geography, customs, culture and political environment in which the employees will be living. Thirdly, employees need to recognize and admit the existence of differences between cultures, the differences in values, beliefs, perceptions, interpretations. Employees should be given a basic cross culture training which will make them aware of the cross culture in the work place. The cross-cultural knowledge training can help in resolving the communication challenges like stereotyping, ethnocentrism, cultural relativism, and cultural shock. Fourthly, a diverse workforce requires efficient communication. MCO leaders must ensure that there are open avenues and platforms for employees to communicate new ideas, grievances, input and feedback. A cultural climate must allow differences to be celebrated rather of merely tolerated. All employees must understand the competitive and moral advantage of diversity. They must respect and support cultural diversity through the recognition of distinctive cultural and religious holidays, open days, weeks, anniversaries, and festival celebrations. Fifthly, in MCOs assignments should be allocated as per experience and interest of the employee. The adjustment to new country becomes easy for the employees especially on their first international assignment, if they are sent to the countries that are similar to their own. Hence, compatibility of assignment with the employee's experience and interest help in addressing the issues of cultural diversity at workplace.

\section{CONCLUSION}

MCOs will continue to proliferate as globalization removes barricades to entre in the nations around the world. People on the other side of the world are no longer a world away. Collaborating with people from diverse cultures is vital to efficacious global business stratagems. Therefore, the key for business is to find methods for people who think in a different way to work with a team spirit. Thus, it is exceptionally significant for the organization to be cognizant of these variances and to have strategies for dealing with any cross-culture communication hurdles that may arise. In a multicultural work milieu, it is ever more important to comprehend the implicit tenets that affect communication styles and to address variances openly and check for clearness and comprehension in order to boost collaboration, achievement, and relationships. In order to work in the international environment, there is a great necessity to develop communication as a sensible skill. To achieve managerial goals and to evade potential risks, the managers should be culturally insightful who should uphold creativity and enthusiasm through flexible leadership. Managing diversity in a MCO is a long way and indeed it requires a new paradigm to guide organizational management. To manage diversity strategically calls for a shift from an efficiency mindset to one with a higher emphasis on human relationship goals. It involves maintaining a balance between meeting the objectives of the MCOs and retaining the individual culture of employees.

\section{REFERENCES}

[1] Binder, J. (2007). Global project management: Communication, collaboration and management across borders. Aldershot, England: Gower Publishing.

[2] Cox, T. (1993) Cultural Diversity in Organizations: Theory, Research, and Practice. San Francisco: Berrett-Koehler.

[3] Galbraith, J.R. (2000).Designing the Global Corporation.San Francisco: Jossey-Bass.

[4] Gardner, J., Paulsen, N., Gallois, C., Callan, V., \& Monaghan, P. (2001).An intergroup perspective on communication in organisations. In H. Giles \& W. P. Robinson (Eds.), The new handbook of languageand social psychology (pp. 561-584). Chichester, UK: Wiley. 
[5] Heyman, M. (2017).Management and multiculturalism in companies.Master's dissertation.Kokkola: Centria University of Applied Sciences.

[6] Iedema, R., \&Wodak, R. (1999). Introduction: Organizational discourses and practices. Discourse and Society, 10, 5-19.

[7] Jenifer, RD \& Raman, GP.(2015). Cross Cultural Communication Barriers in Workplace, International Journal of Management, 6 (1):332-335.

[8] Joshi, A., Labianca, G. and Caligiuri, P.M. (2002) 'Getting Along Long Distance: Understanding Conflict in a Multinational Team through Network Analysis', Journal of World Business 37:277-84.

[9] Kirchmeyer, C. and McLellan, J. (1991) 'Capitalizing on Ethnic Diversity: An Approach to Managing the Diverse Work Groups on the 1990s’, Canadian Journal of Administrative Sciences 8(2): 7-9.

[10] Kirkman, B.L. and Shapiro, D.L. (2001) 'The Impact of Cultural Values on Job Satisfaction and Organizational Commitment in Self-Managing Work Teams: The Mediating Role of Employee Resistance', Academy of Management Journal 44: 557-69.

[11] Kiss, G. 2005. Managing cross-cultural communication challenges, AARMS 4(2): 215-223.

[12] Marquardt, M.J. and Horvath, L. (2001) Global Teams: How Top Multinational Span Boundaries and Cultures with High-Speed Teamwork. Palo Alto, CA: Davis-Black.

[13] McDonough, E. (2001). An investigation of the use of global, virtual, and colocated new product development teams. Journal of Product Innovation Management, 18(2), 110-120.

[14] Rijamampianina, R \& Carmichael, T. (2005). A Pragmatic and Holistic Approach to Managing Diversity. Problems and Perspectives in Management, 3(1):1-15.

[15] Scott, C. R. (1997). Identification with multiple targets in a geographically dispersed organization. Management Communication Quarterly, 10, 491-522.

[16] Singh, D. (2014). Managing Cross-cultural Diversity: Issues and Challenges in Global Organizations, paper read at the International Conference on Recent Trends in Engineering and Management, Trichy, Tamilnadu, India, 11-12 April 2014. http://www.iosrjournals.org/iosr-jmce/papers/ICRTEM/ME/Volume3/IOSRMG002.pdf (Accessed on 15 February 2018).

[17] Sudhiir, MG \&Sudhiir, RG.(2016). Communication Challenges in a Multicultural Organization. International Journal of English language, Literature and Humanities, 4(8):94-102.

[18] Shanthi, D. (2014). Cross Cultural Communication: Its Relevance and Challenges in organizations. International Journal of Research and Development - A Management Review, 1(1):49-51.

[19] Trice, H. M., \& Beyer, J. M. (1993).The cultures of work organizations. Englewood Cliffs, NJ: Prentice Hall.

[20] Tung, R. L. (1993) 'Managing Cross-National and Intra-National Diversity', Human Resource Management 32(4): 461-77.

[21] Vashishtha, SD \&Garg, S. (2014). Multiculturalism: A challenge or an opportunity to managers in Indian perspective. The International Journal of Management, 3(3):1-5.

Citation: Shafaat Hussain. "Managing Communication Challenges in Multicultural Organizations". International Journal of Media, Journalism and Mass Communications (IJMJMC), vol 4, no. 2, 2018, pp. 4449. doi:http://dx.doi.org/10. 20431/2455-0043.0402005

Copyright: (C) 2018 Authors. This is an open-access article distributed under the terms of the Creative Commons Attribution License, which permits unrestricted use, distribution, and reproduction in any medium, provided the original author and source are credited. 